\title{
Significados E Causas Para UMa Terra SONÂMBULA: A FORMAÇÃO DA IDENTIDADE MOÇAMBICANA
}

\author{
Deividy Ferreira dos Santos \\ Universidade Federal de Pernambuco \\ deividyferreira@outlook.com \\ Fabiana Avelino \\ Universidade Cândido Mendes \\ avelinofabiana4@gmail.com
}

Resumen: Considerando que desde el título de la novela Tierra sonámbula, de Mia Couto, se percibe la preponderancia del sueño por escrito, en el presente artículo postulamos que la obra hace referencia a una tierra caracterizada como sonámbula, dado que esta alberga el sueño, la utopía del cambio. Del mismo modo, observamos la construcción de la identidad de los personajes que deambulan por la tierra destrozada, ficción que representa notablemente el actual Mozambique, para verificar cómo la cuestión del sueño asume una representación del rescate y la perpetuación de una identidad cultural.

Palabras clave: Mozambique, Identidad, Sonambulismo, Sueño.

\begin{abstract}
Taking into account that the title of the novel Tierra sonámbula, de Mia Couto, shows the preponderance of dream in writing, we postulate that this work refers to a land described as sleepwalking, since it houses the dream, the utopia of change. In the same way, we observe characters wandering the shattered land and the construction of their identity. This fiction remarkably represents the current Mozambique, in order to verify how the dream assumes a representation of the rescue and perpetuation of a cultural identity
\end{abstract}

Keywords: Mozambique, Identity, Sleepwalking, Dream. 


\section{O sonho visto como um lugar de esperança e busca de um novo tempo}

Segundo Freud (1915), sonhos são fenômenos psíquicos em que realizamos desejos inconscientes. O sonho é o resultado de uma conciliação. Dorme-se e, não obstante, vivencia-se a remoção de um desejo. Satisfaz-se um desejo, porém, ao mesmo tempo, continua-se a dormir. É nesse espaço limítrofe entre a realidade e a imaginação que transitam as personagens de Terra Sonâmbula (1992). Ter sonhos, aqui, significa como ter ainda esperança. $\mathrm{O}$ sonho está ligado à utopia, ao desejo de mudar. Isso se configura logo nas primeiras páginas do livro, pelas epígrafes que abrem o romance. Vejamos, a seguir:

Se dizia daquela terra que era sonâmbula. Porque enquanto os homens dormiam, a terra se movia espaços afora. Quando despertavam, os habitantes olhavam o novo rosto da paisagem e sabiam que naquela noite, eles tinham sido visitados pela fantasia do sonho.

Crença dos habitantes de Matimati. O que faz andar a estrada? É o sonho. Enquanto a gente sonhar a estrada permanecerá viva. É para isso que servem os caminhos, para nos fazerem parentes do futuro.

Fala de Tuahir (Couto, 1992, p. 6).

Tendo em vista o panorama de guerras e devastações que se delineia em Moçambique, a literatura transforma-se em escrita de resistência, ou seja, uma forma de sobrevivência em meio ao caos instaurado no país. Mia Couto, por sua vez, insere na narrativa, elementos que visam o resgate de mitos e sonhos que retratam o passado moçambicano, antes da instauração. A 
elaboração de um sonho, segundo Freud (1915) ocorre porque "existe algo que não quer conferir paz à mente. Um sonho, pois, é a forma com que a mente reage aos estímulos que a atingem no estado de sono" (p. 28). Ou seja, num mundo que se fragmenta, palco de guerras e deslocamentos, descaracterização e abandono, sonhar é buscar refúgio para o sofrimento, é buscar esperança onde não há pistas que levem a ela, é ter a coragem de ousar buscar caminhos para suportar o tormento que parece não ter fim. Nesse contexto, a escrita possibilita o renascimento de uma nação, bem como das personagens presentes na narrativa, que resistiram a um longo desfile de mortes e destruição.

Como relata Fonseca e Cury (2008), a palavra escrita assume-se como local privilegiado de conservação e reinvenção da memória, além de converter-se em possibilidade de retomada do espaço de pertença, de um espaço em que o homem possa se reconhecer. Le Goff (2003), em suas reflexões sobre a memória "observa a memória, não apenas como simples armazenamento de informações do passado, mas como uma apreensão do passado no presente para refletir no futuro, observando como o homem deve se servir da memória para sua libertação no hoje e no porvir" (p. 67). Assim, é através da escritura que as personagens veem sua história sendo retratada, porém, viabilizando através da ficção a idealização de um espaço onde fosse possível voltar a sonhar, a ter esperança de vida e a ver no trágico a luta pela conservação de suas tradições, e, consequentemente, de sua identidade cultural. 
A relação guerra-sonho é uma constante no romance Terra Sonâmbula. Na narrativa em questão, Muidinga e Tuahir, personagens da primeira história do romance, viajam pela estrada destroçada até encontrar em um local de parada um ônibus queimado, denominado "machimbombo". O machimbombo serve de palco para os desdobramentos das histórias do velho e do miúdo, bem como da leitura dos cadernos de Kindzu e, por conseguinte, de outras histórias que surgem através dessa leitura. É no machimbombo que as personagens Muidinga e Tuahir se deparam com vários corpos carbonizados e ao lado de um dos corpos das vítimas encontram uma mala com mantimentos e vários escritos denominados "cadernos de Kindzu".

O contato do velho Tuahir e do menino Muidinga com os despojos da escrita de um morto pela guerra não anuncia um retorno às origens, mas remete a uma convivência densa entre passado e presente, metaforizado através dos cadernos de Kindzu. Temos nestes cadernos uma viajem já concluída que se renova no momento em que é iniciada a leitura dos escritos. São estórias contadas em suas minúcias, com as quais vamos tendo contato pouco a pouco através da leitura que o miúdo faz para Tuahir.

Segundo Ianni (1990), "mesmo os que permanecem, que jamais saem do seu lugar, viajam imaginariamente ouvindo estórias, lendo narrativas, vendo coisas, gentes e signos do outro mundo" (p. 45). Os cadernos de Kindzu possibilitam justamente esse deslocamento imaginário. Muidinga, e mesmo Tuahir, tem acesso através dos escritos a um mundo de questões várias que perpassam em suas próprias vidas: a 
guerra, as mazelas da colonização e o rompimento com o passado colonial. Do mesmo modo que é também, através dos escritos de Kindzu, que um lampejo de esperança e sonho é construído.

Em Terra Sonâmbula é a partir da leitura dos escritos de Kindzu que renasce a esperança de vida em Muidinga e Tuahir, pois ambas voltam a sonhar. Quando as personagens se deslocam do seu espaço real, imaginariamente estabelece-se o que Seixo (1998) chama de paragem:

E viajem inclui também a fase de uma dinâmica mais abrangente: andar em viagem significa no fundo parar em algum sítio, deter-se na via, suspender o caminho (para um olhar, um diálogo, uma apreensão, um gesto, uma escrita, a renovação do viático; paragens) (Seixo, 1998, p. 13).

É na paragem que as personagens estabelecem uma renovação da viajem e a partir de então a paisagem ao redor começa a se modificar. "De fato, a única coisa que acontece é a consecutiva mudança da paisagem. Mas só Muidinga vê essas mudanças da paisagem. Tuahir diz que são miragens, frutos do desejo de seu companheiro" (Couto, 1992, p. 77).

De acordo com Ferza (2009), Freud parte do princípio de que todo sonho tem um significado, embora oculto, da realização de desejos. Desejo de mudança, esperança de vida, reinvenção de um novo espaço, era isso que Muidinga buscava nos cadernos de Kindzu. Eram essas aspirações que faziam a estrada caminhar, provocando mudanças na paisagem, dando novas formas àquele lugar sonâmbulo e devastado pela guerra, devolvendo assim a esperança àqueles errantes personagens que vagavam fugindo da violência e recusando a morte. É 
nesse estado de sonambulismo que transitam as personagens do romance Terra Sonâmbula.

\section{Porque uma Terra "sonâmbula"?}

Uma terra "sonâmbula" porque não pode se fixar num lugar de paz, pois está atravessada por seres errantes, também por uma busca identitária, fugindo da guerra e da morte; uma terra sonâmbula porque abriga o sonho, a utopia da mudança. Nesse sentido, não são apenas os dois companheiros (Muidinga e Tuahir) que escutam as fantasias do caderno de Kindzu e personificam outro espaço, também, a terra morta pela guerra escuta aquelas histórias. Estranho pensar que a estrada morta lhes conferia boa segurança. Era como se, enquanto adormecida, o fantasma da guerra não lhes atingiria. “- Esta estrada está morta!? Mas não entende que isso é muito bom? Esta estrada estar morta é que nos dá boa segurança?" (Couto, 1992, p. 61). A terra, como indicado algumas vezes, encontrase em estado de sono ou letargia; em outras, parece morta, esperando seu despertar que viria com o término da guerra. Eis que a estrada antes fixa, se move. E, quem sabe, a terra não esteja morta? Quem sabe esteja apenas dormindo? E já comece a se mover, sonhambulante, à força dos sonhos de Tuahir, de Muidinga, de Kindzu.

- O que andas a fazer com um caderno?

- Nem sei, pai. Escrevo conforme vou sonhando.

- E alguém vai ler isso?

- Talvez. 
— É bom assim: ensinar alguém a sonhar.

- Mas pai, o que passa com essa nossa terra?

—Você não sabe, filho. Mas enquanto os homens dormem, a terra anda a procurar.

- A procurar o quê, pai?

-É que a vida não gosta sofrer. A terra anda procurar dentro de cada pessoa, anda a juntar os sonhos. Sim, faz conta ela é uma costureira dos sonhos (Couto, 1992, p. 182).

Ainda de acordo com Freud (1915), os sonhos nada mais são do que uma forma particular de pensamento, possibilitada pelas condições do sono. É o trabalho do sonho que cria essa forma, só ele é a essência do sonho - a explicação de sua natureza peculiar. Do mesmo modo, Ford (1999) nos explica noções relativas ao sonho como um mito pessoal:

Temos apenas de fechar os olhos para dormir e aí, no mundo interno do inconsciente, podemos receber todas as noites a visita de formas e forças poderosas do reino mítico. O mito é um sonho coletivo; o sono, um mito pessoal (p. 46).

Esse mundo dos sonhos é buscado na narrativa, pois, através da fantasia, Muidinga cria e recria o universo de Kindzu. De maneira tão intensa que cada aventura narrada nos cadernos chega a se misturar entre a ficção e o real; o seu mundo e o de Kindzu. Essa percepção é visível quando Muidinga propõe a Tuahir brincarem de Kindzu e seu pai, o velho Taímo. Nessa brincadeira, Tuahir faria o papel de Taímo, e Muidinga faria o papel de Kindzu, mas a brincadeira se aprofunda de tal maneira que chega ao ponto de se confundir com a realidade: 
E Muidinga se atrapalha em totais confusões. É como se qualquer coisa, lá no fundo do seu peito, se estivesse rasgando. E se apercebe que, em seu rosto desliza o frio das lágrimas. Depois sente a mão de seu pai lhe afagando a cabeça. Olha o seu rosto e vê que, afinal, seus olhos eram sábios. Foi como se, de repente, toda a bondade dele ficasse visível, redonda (Couto, 1992, p. 188).

Segundo Martins (2003), a linguagem dos sonhos possui suas particularidades que, ao longo dos séculos, mostra-se como um grupo de eventos comuns de uma época radicados na vivência dos povos. Possibilitou ainda, um aprofundamento dos níveis mais ocultos da mente, tornando possível a abordagem de variados sintomas, produtos de um ambiente capaz de oprimir e colocar em risco valores naturais de cada ser. Sonhar é mais do que um simples produto do dia a dia. É revelar-se diante do enigma invisível, mas possível de compreensão. Ou seja, mesmo em meio aos flagelos ocasionados pela guerra, o sonho torna-se capaz de despertar a sensibilidade reprimida, a fragilidade de um povo que terá sido roubado à vontade de viver.

A figura de Taímo, pai de Kindzu, é marcante no romance, sobretudo porque representa a ligação com a terra africana. A fala de Kindzu assinala que algum tipo de rompimento com o pai fosse imprescindível para que ele pudesse seguir viagem. No entanto, ao mesmo tempo, é perceptível um espelhamento em Taímo. Vejamos:

Quando eu tencionava responder, lhe falar da minha entrega aos guerreiros blindados, já meu pai me dava as covas. Mesmo depois de morto, chegado em mim só em sonho, ele me ignorava. Chamei por ele e, voz erguida, me 
expliquei: eu estava a ser guiado por minha vontade. Essa vontade fora ele que me ensinara. Ao fim do cabo, eu estava cumprindo suas silenciosas ordens (Couto, 1992, p. 44).

O abandono às tradições e o desejo de se tornar um naparama fazem com que Kindzu em um de seus sonhos com seu pai Taímo seja amaldiçoado por ele: "O velho Taímo se explicou: eu não podia alcançar nada do sonhado enquanto a sombra dele me pesasse. A mesma coisa se passava com a nossa terra, em divórcio com os antepassados. Eu e a terra sofríamos de igual castigo" (Couto, 1992, p. 45).

A cada momento as narrativas de Muidinga e Kindzu vão se misturando e se entrelaçando. Sente-se esse entrelaçamento a partir do momento em que surge no relato a personagem Farida. Ao encontrar Farida, Kindzu se incumbe de procurar o filho dela, Gaspar. Levada pelos acontecimentos, Farida se isola em um barco que se encontra encalhado, abandonado, como se fosse um barco fantasma. Nesse navio, os dois se encontram e relatam seus sonhos um para o outro. Esse navio pode simbolizar os sonhos impossíveis, uma vez que se encontra encalhado e abandonado como um navio fantasma: "O navio fantasma simboliza os sonhos, de inspiração nobre, mas irrealizáveis, do ideal impossível" (Chevalier, 1999, p. 632).

Nessa metáfora do barco é perceptível também a transmissão das narrativas orais, tão marcantes no romance. Farida lhe diz que o único remédio para ficar boa novamente, após a perda de Gaspar, seria contar sua história: "A mulher se trocou por palavra até quase ser manhã" (Couto, 1992, p. 70). 
Fica claro como as personagens buscam nas narrativas orais e na troca de experiências uma forma de resgatar um passado já perdido. As personagens acabam voltando para lugares já percorridos, mas nunca os veem com o mesmo olhar. Virgínia, a velha que criou Farida, confessa que, como a célebre Sherazade, também "desdobrou os tempos, contando episódios de sua vida. Demorou dias, em detalhes" (Couto, 1992, p. 75).

$\mathrm{O}$ ato de contar histórias, tão presentes nas obras de Mia Couto, remete-nos aos rituais de contação, característicos das tradições moçambicanas. Como aponta Fonseca e Cury (2008), o escritor reitera que, segundo as tradições, os contadores têm formas de abertura e de fechamento dos rituais de contação. As estórias estariam numa caixa, num outro espaço, de onde só poderiam ser retiradas e socializadas por alguém que soubesse cumprir tais rituais. Uma vez partilhadas, as estórias teriam de voltar para o lugar de origem, a caixa pertencente ao primeiro homem e à primeira mulher. Quando não se fecha uma história, a multidão fica contaminada pela doença de sonhar. Tal doença é curada pelo sonho que, como o pharmácon platônico, ocupa o lugar de excêntrica enunciação: veneno e remédio. A literatura seria seu lócus por excelência: "O senhor me deu o maior remédio. Eu voltei a sonhar" (Fonseca e Cury, 2008, p. 180).

Ao que concerne às narrativas de Couto, apropriando-se da metáfora da abertura, também ele, escritor, mistura seu lócus de enunciação, a palavra escrita ao do contador, só que nunca fechando suas narrativas, assumindo radicalmente o lugar da fronteira e da força do sonhar de sua literatura. Artifícios 
reincidentes em sua literatura, o escritor mostra-se delas consciente: "As palavras que movem e que constituem perigo são as palavras que não podem ser ditas em nenhuma língua: as palavras do sonho" (Couto et al., 2008, p. 3).

Nesse sentido, Mia Couto apresenta a escrita não apenas como um veículo condutor para se chegar a uma essência. Mas, sobretudo, como uma viagem de descoberta de outras dimensões e de mistérios que estão para além das aparências. Ou seja, a idealização de um sonho que não se fecha e não se limita.

No último caderno de Kindzu, frustrado por ter falhado em suas duas pretensões: tornar-se um naparama e encontrar Gaspar, Kindzu planeja voltar à aldeia. Em seu último caderno, fala de um sonho que teve. Deita na terra em desfalecimento, deixa cair seus cadernos e segue pela estrada. Aparece um menino, Muidinga, que recolhe seus papéis: "Então, com o peito sufocado, chamo: Gaspar! E o menino estremece como se nascesse por uma segunda vez" (Couto, 1992, p. 204). Aqui, de novo, percebe-se o cruzamento das ideias de sonho e de desfalecimento, bem como a menção ao ato de despertar.

Nesse sentido, nos remete de igual, a forte ligação entre as personagens ao que concerne a busca identitária, ou seja, as personagens se misturam e se completam de tal forma a provocar no leitor a percepção de que ambas são pertencentes a uma mesma identidade. 


\section{A construção da identidade em Terra Sonâmbula, de Mia Couto}

A construção de uma identidade está estritamente ligada à memória, haja vista que esta compreende a capacidade que o ser humano possui de conservar e relembrar experiências e informações relacionadas ao passado e que fazem parte de processos de interação de cada indivíduo com seu meio. Le Goff (2003) acentua alguns elementos de importante relevância no estudo da memória e que copilam para o caráter fundamental da identidade, como algo a ser conquistado, construído:

A memória é um elemento essencial do que se costuma chamar identidade, individual ou coletiva, cuja busca é uma das atividades fundamentais dos indivíduos e das sociedades de hoje, na febre e na angústia. Mas a memória coletiva é não somente uma conquista; é também um instrumento e um objeto de poder. São as sociedades cuja memória social é sobretudo oral ou que estão em vias de constituir uma memória coletiva escrita que melhor permitem compreender esta luta pela dominação da recordação e da tradição, esta manifestação da memória (p. 435, destaque do autor).

Proveniente de um território periférico, marcado pela colonização portuguesa e pela recente guerra civil, Terra Sonâmbula, revela-se de extrema importância para a análise da construção da identidade, tendo em vista que questiona a suposta condição de dependência política e cultural em que se encontram os povos africanos de língua portuguesa, destacando alguns fatos, personagens e datas, a fim de se 
estabelecer uma possível compreensão sobre as marcas simbólicas que fazem parte do conjunto maior em que foi construída a identidade cultural.

Trata-se de uma narrativa atravessada por questões ligadas a problemas que afligiam Moçambique. Como pudemos perceber no capítulo anterior, a guerra que se instalara no país corroborou para uma série de descaracterizações em meio a uma sociedade predominantemente ágrafa, com índice de analfabetismo elevado e permeada pela tradição oral; portanto, a identidade nacional encontra-se num estágio de ruptura, bem como a identidade das personagens que vivenciam todo esse processo de luta pela independência e por uma conseguinte guerra civil:

A consciência da ruptura aberta pelo colonialismo é clara e ilumina a inevitabilidade da situação que mesmo a independência não pôde solucionar. Diante do panorama que se abre, não há regresso, e a sugestão do poeta é só uma: dinamizar o legado, apropriar-se daquilo que outrora foi instrumento de dominação e fonte de angústia (Fonseca e Cury, 2008, p. 51).

Em Terra sonâmbula, transitam personagens em crise identitária, os quais transparecem uma fragmentação em seus sentidos, procedentes à guerra, ilustrando os sonhos construídos em meio às turbulências que os rasuram. Esse panorama contribui para a construção das memórias e, consequentemente, da história destes indivíduos. Jacques Le Goff (2003) aponta a relação entre memória e história, quando salienta: "Tal como o passado não é a história, mas o seu objeto, também a memória não é a história, mas um dos seus objetos e, simultaneamente, um nível elementar de elaboração 
histórica" (p. 51). Assim, a memória também pode ser utilizada para reconstruir os fatos históricos a partir de ressignificações individuais.

Num primeiro momento, podemos analisar a figura do menino Muidinga. Recolhido por Tuahir em um campo de refugiados, Muidinga está em busca de seus pais, pois não conhece seu passado. Trata-se da personagem mais emblemática da narrativa, sobretudo porque está à procura de sua origem e, portanto, de sua própria identidade. Segundo Hall (2006), a identidade é objeto da interação entre o indivíduo e a sociedade e que o sujeito tem sua essência interior, no entanto, é a partir da relação com diversos mundos culturais que sua identidade se estabelece; nesse caso, essa interação inicia-se quando o velho Tuahir o socorre do completo abandono. Assim, ao perceber que o menino está vivo em meio a crianças mortas, ajuda-o em seu recomeço e, de certa forma, o educa novamente: "O velho teve que lhe ensinar todos os inícios: andar, falar, pensar. Muidinga se meninou outra vez" (Couto, 1992, p. 10). A busca de Muidinga por sua origem é bastante explícita no romance e, é perceptível que precocemente o pequeno sofrera conflitos identitários.

Ao apropriar-se dos cadernos de Kindzu, Muidinga descobre que sabe ler. A leitura de um texto de outrem ativa no miúdo seu processo de autoconhecimento, como se a vida e a trajetória de Kindzu representasse uma luz a iluminar-lhe a consciência e os vazios deixados na memória:

Depois se senta ao lado da fogueira, ajeita os cadernos e começa a ler. Balbucia letra a letra, percorrendo o lento 
desenho de cada uma. Sorri com satisfação de uma conquista. Vai-se habituando, ganhando despacho.

- Que estás a fazer, rapaz?

- Estou a ler.

- É verdade, já esquecia. Você era capaz de ler (Couto, 1992, p. 13).

As duas narrativas passam, então, a ser narradas paralelamente durante toda a obra. As histórias de Muidinga e de Kindzu se confundem na mesma frequência que se completam, do mesmo modo que ocorre entre a história e a ficção, já que são acontecimentos que remetem a realidade. Kindzu, por sua vez, é também uma personagem em busca de uma nova identidade. Um episódio que atravessa seu primeiro caderno nos revela uma metáfora intrigante a respeito da temática da guerra e a fragilidade em que ela coloca o país, os povos e as famílias, incluindo a sua própria. Trata-se da quebra de um pote, que nos indica precisamente a forte sensação de estilhaçamento pessoal e familiar vivenciada pela personagem:

Depois, os tiroteios foram chegando mais perto e o sangue foi enchendo nossos medos. A guerra é uma cobra que usa os nossos próprios dentes para nos morder. Seu veneno circulava agora em todos os rios da nossa alma. De dia já não saímos, de noite não sonhávamos. O sonho é o olho da vida. Nós estávamos cegos. Aos poucos eu sentia a nossa família quebrar-se como um pote lançado no chão. Ali onde eu sempre tinha encontrado meu refúgio já não restava nada (Couto, 1992, p. 10).

Em meio a essa desestruturação identitária que perpassa a vida de Kindzu e a perda da sua família e de seu amigo indiano, a personagem resolve seguir outro rumo e juntar-se 
aos naparamas - os guerreiros que lutavam contra a guerra que assolava o país. "Única saída era sozinhar-me por minha conta, antes que me empurrassem para esse fogo que lá fora, consumia tudo" (Couto, 1992, p. 28). Enquanto Kindzu relata sua saga para se tornar um naparama e parte de sua aldeia como um homem de viagem, de acordo com a definição do feiticeiro, Muidinga se debruça nos cadernos de Kindzu para fazer questionamentos sobre si mesmo.

Uma cena rica de significados e que merece destaque no romance a esse respeito, é o momento em que Muidinga descobre que sabe escrever e o faz gradualmente, assim como se dá a busca por sua própria identidade. Iniciar o seu processo pessoal de construção da identidade através do domínio da linguagem para, então, de certa forma entrar em contato com o mundo letrado e com o universo da escrita a partir dos cadernos deixados por Kindzu permite ao menino tornar-se outro:

Então ele com um pequeno pau rabisca na poeira do chão: "AZUL". Fica a olhar o desenho, com a cabeça inclinada sobre o ombro. Afinal, ele também sabia escrever? Averiguou as mãos quase com medo. Que pessoa estava em si e lhe ia chegando com o tempo? Esse outro gostaria dele? Chamar-se ia Muidinga? Ou teria outro nome, desses assimilados, de usar em documento? (Couto, 1992, p. 37).

A narrativa é permeada por aventuras, em que coabitam vários elementos, tanto da cultura tradicional e local, como da história do país. Fato é que até mesmo a proclamação da Independência de Moçambique, torna-se um de seus personagens fantásticos: Vinticinco de Junho, o Junhito, irmão de Kindzu, que sofrera uma metamorfose até se transformar 
em galinha. Em determinado momento, Muidinga chega a confundir-se com Junhito: "Vou dizer. Estou a pensar eu sou Junhito" (Couto, 1992, p. 39).

Essa identificação do miúdo com o irmão de Kindzu é interessante visto que Junhito sofrera uma transformação substancial em sua própria identidade, perdendo as características que o definiam como ser humano. Seu pai, Taímo, "fez seguir ordens de seu mandamento: o miúdo devia mudar, alma e corpo, na aparência de galinha" (Couto, 1992, p. 18). A ordem do pai foi tão indiscutível que, depois de sua conversão, "Junhito já nem sabia soletrar as humanas palavras" (Couto, 1992, p. 19). Dessa maneira, podemos relacionar esse fenômeno ao que ocorre com Muidinga, uma vez que, inicialmente, ele também se encontrava carente de uma identidade, a qual foi sendo construída aos poucos. Por esse ângulo, Muidinga identifica-se com a história de Junhito por se reconhecer na figura daquele menino que terá a identidade e a memória roubada em meio aos conflitos que perpassavam o país.

As viagens empreendidas por Kindzu e Muidinga correm paralelas para, no final, entrelaçarem-se. Em seu último capítulo, como já mencionamos no tópico anterior, Kindzu fala de um sonho que teve. Deita na terra em desfalecimento, deixa cair seus cadernos e segue pela estrada. Aparece um menino, Muidinga, que recolhe seus papéis: "Então, com o peito sufocado, chamo: Gaspar! E o menino estremece como se nascesse por uma segunda vez" (Couto, 1992, p. 204). 
Os cadernos, portanto, possuem um significado emblemático e iniciático. São capazes de estabelecer um vínculo entre o presente e o passado e de ligar a trajetória dos mais jovens aos mais velhos, isto é, aos homens e as mulheres de outras gerações, que já contaram suas histórias e depositaram seu saber nesses mesmos cadernos. O velho Tuahir já havia anunciado que "os escritos de Kindzu traziam ao jovem uma memória emprestada sobre esses impossíveis dias" (Couto, 1992, p. 136).

A obtenção dessa memória resgata o menino e o velho da solidão tão marcante daquele tempo. Assim, Muidinga pôde construir seu passado, ainda que imaginário e compreender que a identidade não se recebe única e passivamente no dia do nascimento, mas é algo que o indivíduo deve construir ao longo de sua vida. Como afirma Le Goff (2003): "uma vez que a identidade muda de acordo com a forma como o sujeito é interpelado ou representado, a identificação não é automática, mas pode ser ganhada ou perdida" (p. 21). Esse processo é enfrentado gradativamente tanto por Muidinga quanto por Kindzu no decorrer da narrativa.

Apropriar-se dos cadernos de Kindzu possibilitou a Muidinga nascer outra vez, como se alcançasse a consciência de que o passado mais do que uma verdade inquestionável estabelecida pela tradição, trouxesse em si a fragilidade do sonho e das histórias contadas pelos vários narradores a quem Kindzu coletou os relatos. No entanto, o desfecho final do romance Terra Sonâmbula faz um paralelo com o leitor: abre a possibilidade de que, de uma maneira ou de outra, Kindzu tenha de fato reencontrado o filho de Farida e que 
Muidinga/Gaspar tenha descoberto sua história. Entretanto, esse jogo não deixa também de indicar como Muidinga construiu sua biografia, mesmo que seja através de uma identidade que lhe fora emprestada.

Nesse sentido, concluímos que a narrativa se encontra num estado de sonambulismo, adormecido enquanto a guerra não terá fim. Nesse espaço limítrofe entre a realidade e a ficção é possível instaurar uma concepção assegurada no sonho da construção de um espaço novo; espaço no qual as personagens possam se reconhecer, onde fosse possível apoderar-se de uma identidade que foi fragmentada pela guerra, uma memória estilhaçada e uma ruptura cultural com a tradição oral e, consequentemente, com os valores ancestrais. A transição entre presente e passado, velho e novo, tradicional e moderno, se misturam e se completam de maneira a enriquecer a obra coutiniana, de modo a refletir numa escritura literária com estética nacional, porém viabilizando uma cultura local.

\section{Referências Bibliográficas}

Chevalier, J.; Gheerbrant, A. (1999). Dicionário de símbolos: mitos, sonhos, costumes, gestos, formas, figuras, cores, números. Tradução de Vera da Costa Silva e outros. Rio de Janeiro: J. Olympio Editora.

Couto, M. (1992). Terra Sonâmbula. São Paulo, Companhia das Letras. 
Fonseca, M. N. S. (2008). "Velho e velhice nas literaturas africanas de língua portuguesa”. Literaturas africanas de Língua Portuguesa: Percursos da memória e outros trânsitos. Belo Horizonte: Veredas e Cenários, 131-149.

Fonseca, M. N. S.; Cury, M. Z. F. (2008). Mia Couto: espaços ficcionais. Belo Horizonte: Autêntica.

Ford, C. (1999). O herói com rosto africano: mitos da África. São Paulo: Summus. (Selo Negro).

Freud, S. (1915). A Interpretação de Sonhos. Rio de Janeiro: Imago.

Ianni, O. (1990). “A metáfora da viajem”. Cultura Vozes, 90 (2).

Le Goff, J. (2003). História e Memória. Campinas, São Paulo: Editora da UNICAMP.

Seixo, M. A. (1998). Poéticas da viagem na literatura. Lisboa: Cosmos.

Fecha de recepción: 22/10/2019

Fecha de aprobación: 15/06/2020 